\title{
Prevalência de anticorpos contra o vírus da mamilite herpética em bovinos do Rio Grande do Sul, Brasil
}

\author{
Prevalence of antibodies to bovine herpes mammillitis virus in cattle of Rio Grande do Sul, Brazil
}

\author{
Fabrício Dias Torres ${ }^{\mathrm{I}}$ Lucas Machado Bernardes ${ }^{\mathrm{II}}$ Rudi Weiblen ${ }^{\mathrm{II}}$ \\ Eduardo Furtado Flores ${ }^{\mathrm{II}} *$
}

\begin{abstract}
O herpesvírus bovino tipo 2 (BoHV-2), agente da mamilite herpética bovina (BHM), possui distribuição mundial e foi identificado no Brasil, na década de 70. A partir de então, casos de mamilite clinicamente compatíveis com a BHM têm sido relatados por técnicos e produtores, o que sugere a presença e disseminação do agente no rebanho bovino brasileiro. Este trabalho relata um inquérito sorológico da infecção pelo BoHV-2 no Estado do Rio Grande do Sul (RS), em amostras coletadas como parte do Programa Nacional de Controle e Erradicação da Brucelose e Tuberculose (PNCBT). Um total de 2.213 amostras de soro coletadas de fêmeas bovinas com idade igual ou superior a 24 meses, predominantemente de rebanhos leiteiros, de 136 municípios pertencentes a sete macrorregiões do RS, foram testadas para anticorpos antiBoHV-2 pela técnica de soro-neutralização (SN). Anticorpos anti-BoHV-2 (títulos > 2) foram detectados em 24,5\% (543/ 2.213) das amostras. Os índices de positividade variaram entre 12,9\% (22/170), na região metropolitana de Porto Alegre, e 48,9\% (69/137), na região centro oriental do RS. Em geral, os rebanhos leiteiros apresentaram prevalência maior (32,3\%), seguidos dos rebanhos mistos (22\%) e de corte (17,6\%). Esses resultados demonstram uma ampla disseminação da infecção pelo BoHV-2 no rebanho bovino do Estado e sugerem a participação do agente em parte dos casos de mamilite descritos em gado leiteiro.
\end{abstract}

Palavras-chave: herpesvírus bovino 2, BoHV-2, mamilite herpética, soroprevalência.

\section{ABSTRACT}

Bovine herpesvirus type 2 (BoHV-2), the agent of bovine herpetic mammillitis (BHM), has a worldwide distribution and was identified in Brazil in the 70's. Thereafter, cases of bovine mammillitis clinically compatible with BHM have been frequently reported by cattle owners and veterinarians, mainly in dairy herds, suggesting the dissemination of BoHV-2 among Brazilian cattle. This article reports a serologic survey for BoHV-2 antibodies in cattle from Rio Grande do Sul (RS), using serum samples obtained upon a statistically planned sampling as a part of the Program of Control/Eradication of Brucellosis and Tuberculosis (PNCBT). A total of 2.213 serum samples from cows with 24 months or older, predominantly from dairy herds, from 136 counties located in seven geographical regions of RS were tested by virus neutralization (VN). Serum samples with $V N$ titers $>2$ were detected in $24.5 \%$ (543/2.213) of the animals. Prevalence rates varied from $12.9 \%$ (22/170) in Porto Alegre metropolitan area to 48,9\% (69/137) in the central-eastern region. In most regions, the highest prevalence rates were observed in dairy herds $(32.3 \%)$, followed by double proposit (22\%) and beef herds (17.6\%). These results demonstrate that BoHV-2 infection is widespread among cattle in RS, and potentially involved in cases of mammillitis described in dairy cows.

Key words: bovine herpevirus 2, BoHV-2, herpetic mammillitis, seroprevalence.

O herpesvírus bovino tipo 2 (BoHV-2), também conhecido como vírus da mamilite herpética, é um vírus DNA, com envelope, pertencente ao gênero

IPrograma de Pós-graduação em Medicina Veterinária, Universidade Federal de Santa Maria (UFSM), Santa Maria, RS, Brasil. ${ }^{\text {II } C u r s o ~ d e ~ M e d i c i n a ~ V e t e r i n a ́ r i a, ~ U F S M, ~ S a n t a ~ M a r i a, ~ R S, ~ B r a s i l . ~}$

IIISetor de Virologia, Departamento de Medicina Veterinária Preventiva (DMVP), Centro de Ciências Rurais (CCR), UFSM, 97105900, Santa Maria, RS, Brasil. E-mail: flores@ccr.ufsm.br. *Autor para correspondência. 
Simplexvirus, subfamília Alphaherpesvirinae, família Herpesviridae (ROIZMAN et al., 1992). Uma propriedade biológica importante dos alfaherpesvírus é a capacidade de estabelecer e reativar infecções latentes e, dessa forma, se manter na natureza (FLORES, 2007). A infecção pelo BoHV-2 tem sido associada a duas formas clínicas distintas e bem definidas: lesões vesiculares e erosivas localizadas nas tetas ou no úbere (mamilite herpética) e lesões nodulares disseminadas na pele (pseudo lumpy skin disease) (GIBBS \& RWEYEMAMU, 1977). As lesões nos tetos e no úbere podem ser confundidas com outras infecções víricas de pele, principalmente as causadas pelo vírus pseudocowpox e pelo vírus da vaccinia (LOBATO et al., 2005). Essas lesões dificultam a ordenha, predispõem a mastites, resultam em redução da produção leiteira e, ocasionalmente, podem levar ao descarte prematuro das vacas afetadas (GIBBS \& RWEYEMAMU, 1977). Não existem vacinas comerciais disponíveis contra o BoHV-2, e as medidas de controle baseiam-se no isolamento dos animais afetados e em cuidados para evitar a transmissão do agente (SMEE \& LEONHARDT, 1994). Uma vez introduzida em um rebanho, a infecção pode se perpetuar por meio dos portadores da infecção latente, que ocasionalmente reativam a infecção e a transmitem a animais susceptíveis (GIBBS et al., 1973).

A mamilite herpética bovina (bovine herpetic mammillitis, BHM) já foi descrita em vários países e, em alguns deles, parece possuir importante repercussão sanitária e econômica, sobretudo em gado leiteiro (GIBBS \& RWEYEMAMU, 1977; SMEE \& LEONHARDT, 1994). No Brasil, dois relatos das décadas de 70 e 80 demonstraram a presença da infecção (ALICE, 1977; CASTRO et al., 1988). Apesar da falta de publicações mais recentes sobre a ocorrência da infecção no país, casos de mamilite com características clínicas compatíveis com a infecção pelo BoHV-2 têm sido frequentemente relatados por veterinários de campo (PITUCO, E. M. 2004, informe verbal; KREUTZ, L.C., 2006, informe verbal). Assim, o objetivo do presente trabalho foi investigar a prevalência de anticorpos contra o vírus da mamilite herpética em bovinos, no Rio Grande do Sul (RS).

Foram utilizadas 2.213 de um total de aproximadamente 18.000 amostras de soro coletadas de fêmeas bovinas com idade igual ou superior a 24 meses, por meio de um desenho amostral executado como parte do Programa Nacional de Controle e Erradicação da brucelose e Tuberculose (PNCBT). As amostras foram disponibilizadas pelo Instituto de Pesquisas Veterinárias Desidério Finamor (IPVDF). As amostras eram oriundas de rebanhos localizados em 136 municípios e foram separadas proporcionalmente em micro- e mesorregiões dentro de sete macrorregiões, conforme levantamento efetuado pela Secretaria de Agricultura e Abastecimento (SAA) do RS. Do total do rebanho de cada região, foram alocadas de maneira aleatoriamente $0,016 \%$ das amostras, sendo agrupadas em categorias (rebanho de leite, dupla aptidão e corte). A amostragem é representativa do rebanho bovino do Rio Grande do Sul, seguindo desenho experimental descrito por HOLZ et al. (2009).

As amostras foram testadas em duplicata pela técnica de soro-neutralização ( $\mathrm{SN}$ ), na qual foram incubadas diluições 1:2 de cada amostra de soro com 100 doses infectantes para $50 \%$ dos cultivos celulares (DICC ${ }_{50}$ ) do BoHV-2 (isolado norte-americano cedido pelo Dr. Fernando Osório, Universidade de Nebraska, Lincoln) durante $2 \mathrm{~h}$, seguindo-se a adição de uma suspensão de células de linhagem de rim bovino (CRIB) e incubação a $33^{\circ} \mathrm{C}$ em atmosfera de $5 \% \mathrm{CO}_{2}$. A leitura do teste foi realizada após $96 \mathrm{~h}$ de incubação pelo monitoramento do efeito citopático. A técnica de SN para o BoHV-2 foi descrita com detalhes por ALMEIDA et al. (2008).

Os resultados apresentados na tabela 1 demonstram índices variáveis de soropositivos para o BoHV-2 nas regiões amostradas. Os maiores índices de positividade foram observados na região centrooriental, que abrange a região de Santa Cruz, Lajeado e Estrela (48,9\%) e na região noroeste (48,2\%), igualmente caracterizada pela existência de minifúndios e atividade leiteira desenvolvida. Os menores índices foram observados em regiões tradicionalmente dedicadas à pecuária de corte extensiva, como as regiões sudeste $(19,7 \%)$ e sudoeste (22,6\%). Em praticamente todas as regiões, observou-se a tendência de os rebanhos leiteiros apresentarem soroprevalência superior aos rebanhos mistos e de corte (Tabela 1). Embora relatos na literatura indiquem que rebanhos de corte também são afetados pelo BoHV-2, nesses rebanhos a infecção provavelmente possui repercussão econômica inferior à observada em gado leiteiro (GIBBS et al., 1973; SCOTT \& MARTIN, 1978).

Os níveis de soropositividade observados revestem-se de especial importância, sobretudo porque sorologia positiva aos herpesvírus, em ausência de vacinação, indica a condição de portador (FLORES, 2007). Assim como em outras infecções herpéticas, o vírus permanece de forma latente nos hospedeiros após a infecção aguda, podendo ser reativado e re-excretado ocasionalmente (GIBBS et al. 1973). Estudos recentes em ovelhas - propostas como modelo experimental demonstraram a presença de DNA do BoHV-2 em gânglios lombares durante a infecção latente, além de linfonodos regionais. Embora não tenha sido possível 
Tabela 1 - Prevalência de anticorpos neutralizantes contra o herpesvírus bovino tipo 2 (BoHV-2) em bovinos, do Rio Grande do Sul.

\begin{tabular}{|c|c|c|c|c|c|c|c|c|}
\hline Macrorregião & Leite & $\%$ & Misto & $\%$ & Corte & $\%$ & Total & $\%$ \\
\hline Noroeste $(49)^{\mathrm{a}}$ & $94 / 329$ & $(28,6)$ & $12 / 57$ & $(21,1)$ & $2 / 26$ & $(7,7)$ & $108 / 412$ & $(26,2)$ \\
\hline Nordeste (11) & $48 / 97$ & $(49,5)$ & $20 / 44$ & $(45,5)$ & $\ldots$ & & $68 / 141$ & $(48,2)$ \\
\hline Centro Ocidental (14) & $11 / 47$ & $(23,4)$ & $27 / 179$ & $(15,0)$ & $0 / 20$ & $(0)$ & $38 / 246$ & $(15,4)$ \\
\hline Centro Oriental (13) & $32 / 81$ & $(39,5)$ & $35 / 51$ & $(68,6)$ & $0 / 5$ & (0) & $67 / 137$ & $(48,9)$ \\
\hline Metropolitana de Porto Alegre (18) & $8 / 62$ & $(12,9)$ & $8 / 88$ & $(9,1)$ & $6 / 20$ & (30) & $22 / 170$ & $(12,9)$ \\
\hline Sudoeste (14) & $40 / 117$ & $(34,2)$ & $20 / 149$ & $(13,4)$ & $113 / 501$ & $(22,6)$ & $173 / 767$ & $(22,6)$ \\
\hline Sudeste (17) & $40 / 111$ & (36) & $24 / 97$ & $(24,7)$ & $3 / 132$ & $(2,3)$ & $67 / 340$ & $(19,7)$ \\
\hline (136 municípios) & $273 / 844$ & $(32,3)$ & $146 / 665$ & (22) & $124 / 704$ & $(17,6)$ & $543 / 2213$ & $(24,5)$ \\
\hline
\end{tabular}

a Número de municípios amostrados.

b Não amostrado.

provocar a reativação e excreção viral pela administração de corticosteróides, acredita-se que eventos de reativação e excreção viral, que acompanham episódios de estresse por causas diversas, sejam importantes para a transmissão e manutenção do vírus no ambiente natural (TORRES et al., 2008). A inexistência de vacinas comerciais contra o BoHV-2, aliada à ausência de reatividade sorológica entre o BoHV-2 e outros herpesvírus de ruminantes, também corroboram a observação de que o índice de $24,5 \%$ de positividade detectado no presente estudo representa a prevalência de animais portadores da infecção latente.

Em um estudo prévio, foram detectados níveis de soropositividade semelhantes em bacias leiteiras do RS (27\%) e do Paraná (29,8\%) (ALMEIDA, S.R. informe verbal). Índices altos de prevalência foram detectados também em outros países, tais como o Kênia (33,3\%; MARTIN \& GWYNNE, 1968) e a Holanda (37,7\%; SCOTT \& MARTIN, 1978). Os índices de soropositividade observados no presente estudo corroboram informações de veterinários de campo, que relatam a ocorrência frequente de mamilite em vacas leiteiras (PITUCO, E. M. 2004, informe verbal; KREUTZ, L.C., 2006, informe verbal) . As características clínicas descritas geralmente são compatíveis com a enfermidade causada pelo BoHV-2, embora outras infecções virais também possam cursar com quadros clínicos semelhantes, incluindo as causadas pelo vírus vaccinia e vírus da pseudovaríola, infecções também já identificadas no Brasil e de caráter zoonótico (JACKSON, 1993; LOBATO et al., 2005). Devido à possível ocorrência dessas infecções que produzem quadros clínicos semelhantes à BHM, estudos adicionais envolvendo rebanhos de outros Estados são necessários para fornecer dados mais abrangentes sobre a situação real e a relevância da infecção pelo BoHV-2 no rebanho leiteiro do país.
A importância sanitária da mamilite herpética é reconhecida em diversos países, principalmente em rebanhos leiteiros. O manejo intensivo desses animais pode favorecer a disseminação do vírus e da enfermidade. Acredita-se que a aglomeração de animais, aliada a determinadas práticas de manejo durante a ordenha, sejam importantes para a disseminação do agente (GIBBS \& RWEYEMAMU, 1977; SCOTT \& MARTIN, 1978).

Durante a análise dos dados do presente estudo, um padrão de distribuição das amostras positivas ficou bem evidente: a concentração de amostras positivas em determinadas propriedades nas quais uma grande parte dos animais era reagente contrastando com propriedades negativas, muitas vezes localizadas na mesma macrorregião. Esse tipo de distribuição - a ocorrência de rebanhos positivos e negativos numa mesma região, muitas vezes com proximidade geográfica - é característico de infecções que são transmitidas por contato direto ou indireto (FLORES, 2007). Embora as formas de transmissão do BoHV-2 ainda não sejam bem conhecidas, acredita-se que a transmissão ocorra principalmente por contato indireto, ou de forma indireta, com a participação das mãos dos ordenhadores, dos copos das ordenhadeiras e, mesmo, com a participação de insetos (moscas, mosquitos), que atuariam como vetores mecânicos (GIBBS et al., 1973). Assim, a transmissão entre rebanhos, mesmo vizinhos, aparentemente não ocorre com frequência, ao contrário de transmissão entre animais de um mesmo rebanho, que parece ser mais frequente. Com isso, a introdução de animais doentes ou latentemente infectados parece representar a maior fonte de disseminação da mamilite herpética entre rebanhos (GIBBS et al., 1973). 
Em resumo, os resultados dos testes sorológicos indicam que a infecção pelo BoHV-2 está amplamente difundida no rebanho bovino do Estado do RS e que os rebanhos leiteiros apresentam uma prevalência maior do que os rebanhos mistos e de corte. Após os primeiros relatos nas décadas de 70 e 80, este trabalho confirma a presença e disseminação do vírus no país.

\section{AGRADECIMENTOS}

À SAA-RS e ao IPVDF, pelo fornecimento das amostras. Ao Conselho Nacional de Desenvolvimento Científico e Tecnológico (CNPq), pelas bolsas. F.D.T é bolsista de mestrado e L.M.B é bolsista de iniciação científica. E.F.F. [352386/967] e R.W. [520011/95] são bolsistas PQ do CNPq.

\section{INFORME VERBAL}

PITUCO, E. M. Agencia Paulista de Tecnologia do Agronegócio - Apta. Av. CONSELHEIRO RODRIGUES ALVES, 1252 VILA MARIANA 04014-002 - Sao Paulo, SP - Brasil. Fone: (11) 50871786 Email: pituco@biologico.sp.gov.br

KREUTZ, L. C. Universidade de Passo Fundo (UPF), Faculdade de Agronomia e Medicina Veterinária, Hospital Veterinário. CENTRO 99001-970 - Passo Fundo, RS - Brasil. Fone: (54) 3168161 Ramal: 8160 Fax: (54) 316 8152. Email: lckreutz@pq.cnpq.br

\section{REFERÊNCIAS}

ALICE, F.J. Isolamento do vírus da mamilite herpética bovina no Brasil. Rev Microbiol, v.8, p.9-15, 1977.

ALMEIDA, S.R. et al. Clinical and pathological characterization of acute mammillitis in lactating ewes inoculated with bovine herpesvirus 2. Pesq Vet Bras, v.28, p.87-94, 2008. Disponível em:<http://www.scielo.br/scielo.php?pid=S0100736X2008000100014\&script=sci_arttext\&tlng $=\mathrm{e}>$. Acesso em: 19 out. 2008. Doi: 10.1590/S0100-736X2008000100014

CASTRO, R.S. et al. Relato de um surto de "pseudo lumpy skin disease" em novilhas importadas, em Minas Gerais, Brasil. Arq Bras Med Vet Zoot, v.40, n.4, p.305-311, 1988.
FLORES, E.F. Epidemiologia das infecções víricas. In: FLORES, E.F. (Org). Virologia veterinária. Santa Maria:UFSM, 2007. p.261-294.

GIBBS, E.P. et al. Experimental studies of the epidemiology of bovine herpes mammillitis. Res Vet Sci, v. 14, p. 139-144, 1973.

GIBBS, E.P.; RWEYEMAMU, M.M. Bovine herpesviruses. Part II. Bovine herpesviruses 2 and 3. Vet Bull, v.47, p.411425, 1977.

HOLZ, C.L. et al. Prevalência de herpesvírus bovinos tipos 1 e 5 no Estado do Rio Grande do Sul. Pesq Vet Bras, no prelo 2009.

JACKSON, P. Differential diagnosis of common bovine skin disorders Part 1. In Pract, v.15, n.3, p.119-127, 1993.

LOBATO, Z.I.P. et al. Surto de varíola bovina causada pelo vírus Vaccinia na região da Zona da Mata Mineira. Arq Bras Med Vet Zoot, v.57, n.4, p. 424-429, 2005. Disponivel em: <http:// www.scielo.br/scielo.php?script=sci_arttext\&pid=S0102$09352005000400001 \& \operatorname{lng}=$ en\&nrm=iso\&tlng=pt $>$. Acesso em: 13 Ago 2007. Doi: 10.1590/S0102-09352005000400001.

MARTIN, W.B.; GWYNNE, M. Antibodies to the group II lumpy skin disease virus in the sera of cattle in Kenya. Bull Epiz Dis Africa, v.16, p.217-222, 1968.

ROIZMAN, B. et al. The family Herpesviridae: an update. Arch Virol, v.123, p.425-488, 1992.

SCOTT, F.M.; MARTIN, W.B. Antibodies to bovid herpesvirus 2 in the sera from cattle in the Netherlands. Vet Rec, v.102, p.464, 1978.

SMEE, D.F.; LEONHARDT, J.A. Vaccination against bovine herpes mammillitis virus infections in guinea pigs. Intervirol, v.27, p.20-24, 1994. Disponível em: <http:// content.karger.com/ProdukteDB/produkte.asp?Doi=150351>. Acesso em: 11 Ago. 2008. Doi: 10.1159/000150351.

TORRES, F.D. et al. Distribution of latent bovine herpesvirus 2 DNA in tissues of experimentally infected sheep. Res Vet Sci, impresso. Disponível em: <http://www.ncbi.nlm.nih.gov/ pubmed/19157471>. Acesso em: 27 Jan. 2009. Doi:10.1016/ j.rvsc.2008.12.003. 